\title{
O Meteorito Bendegó: história, mineralogia e classificação química
}

\author{
Wilton Pinto de Carvalho ${ }^{1}$, Débora Correia Rios ${ }^{1,2}$, Herbet Conceição ${ }^{2,3}$, \\ Maria Elizabeth Zucolotto ${ }^{4}$ \& Massimo D'Orazio ${ }^{5}$
}

\begin{abstract}
Resumo O meteorito Bendegó, uma massa de ferro e níquel com $5.360 \mathrm{~kg}$, é o maior exemplar da coleção brasileira e detentor de uma rica história de contribuições à ciência meteorítica. Sua descoberta em 1784 no sertão da Bahia, sua épica remoção para o Museu Nacional (Rio de Janeiro) no final do século XIX e sua participação em estudos que estabeleceram a classificação química dos meteoritos metálicos na década de 1970 credenciam esse visitante espacial a reafirmar junto à comunidade geológica brasileira a importância dessas amostras extraterrestres que são autênticos arquivos repletos de informações sobre o que ocorreu nos primórdios do sistema solar e nos processos de diferenciação química dos planetas e asteróides. Este artigo estuda esse meteorito em seus contextos histórico, cósmico, geológico, petrológico e geoquímico lançando mão de técnicas analíticas avançadas a exemplo da análise por ativação de nêutrons, a espectroscopia de massa indutivamente acoplada a plasma e a microscopia eletrônica de varredura para melhor caracterizar as propriedades dessa massa de $\mathrm{Fe}-\mathrm{Ni}$ que algum dia era parte integrante do núcleo de um objeto espacial suficientemente grande para experimentar um processo de diferenciação química.
\end{abstract}

Palavras-Chave: Bendegó, meteorito, meteorítica, Bahia, ferro.

\begin{abstract}
The Bendego meteorite: history, mineralogy and chemical classification The Bendegó meteorite, an iron and nickel mass weighting $5,360 \mathrm{~kg}$, is the largest specimen in the Brazilian collection and holds a rich record of contributions to the meteoritic science. Its finding in 1784 in the hinterland of Bahia State, its epic transportation to the National Museum (Museu Nacional, Rio de Janeiro) in the end of the XIX century, and its participation in the studies which lead to the chemical classification of the metallic meteorites in the $70^{\prime}$ s, grant to this space visitor enough credibility to reinforce to the Brazilian geologic community the importance of those extraterrestrial samples, which are authentic records of the beginning of the solar system and early chemical differentiation processes of planets and asteroids. This paper presents new insights regarding the Bendegó historic, cosmic, geologic, petrologic and geochemical context and takes advantage from modern analytical methods, such as the instrumental neutron activation analysis, mass inductively coupled plasma spectroscopy, and scanning electronic microscopy, to better characterize the properties of such a Fe-Ni mass which, someday, would be the core of a space object, big enough to experiment a chemical differentiation process.
\end{abstract}

Keywords: Bendego, meteorite, meteoritic, Bahia, iron.

INTRODUÇÃ̃o O meteorito Bendegó, pesando $5.360 \mathrm{~kg}$, é o maior espécime dentre os 57 exemplares que compõem a coleção brasileira de rochas e fragmentos de ferro de origem espacial (Tab. 1, Carvalho \& Zucolotto 2008). Ocupa a $16^{\mathrm{a}}$ posição entre as maiores massas individuais catalogadas em todo o mundo. Os primeiros estudos sobre esse siderito foram publicados há mais 100 anos, quando Derby discorreu sobre suas características físicas, mineralógicas e químicas utilizando análises realizadas no final do século XIX (Derby 1896), confirmando sua classificação estrutural como um octaedrito grosso (Rose 1864). Contudo, apenas na década de 1970 o Bendegó foi considerado pertencente ao tipo IC, um grupo genético de sideritos, conforme classificação química para os meteoritos de ferro proposta por John Wasson e seus colegas da Universidade da Califórnia, Los Angeles (Scott \& Wasson 1976, Buchwald 1975, Scott 1977).

A descoberta do meteorito Bendegó ocorreu no final do século XVIII (1784), aflorando a 180 metros do leito do riacho Bendegó, na região onde hoje situam-se os município de Monte Santo e Uauá, interior da Bahia. Essa descoberta ocorreu dez anos antes da publicação do livro pioneiro de Chladini sobre a importância científica dos meteoritos através do estudo do meteorito Palas (Chladini 1794, McCall et al. 2005). No mundo, as primeiras análises químicas de meteoritos só foram divulgadas no início do século

1 - Curso de Pós-Graduação em Geologia, Laboratório de Petrologia Aplicada à Pesquisa Mineral (GPA), Instituto de Geociencias, Universidade Federal da Bahia. Salvador (BA), Brasil. E-mail: wilton@atarde.com.br, debora.rios@pq.cnpq.br

2 - Conselho Nacional de Desenvolvimento Científico e Tecnológico (CNPq). Bolsista de Produtividade em Pesquisa.

3 - Universidade Federal de Sergipe - Aracaju (SE), Brasil. E-mail: herbet@pq.cnpq.br

4 - Universidade Federal do Rio de Janeiro - Museu Nacional, Rio de Janeiro (RJ), Brasil. E-mail: mezucolotto@globo.com

5 - Dipartimento dei Scienze della Terra, Universitá di Pisa, Via Santa Maria 53, 56126 Pisa, Italy. E-mail: dorazio@dst.unipi.it 
Tabela 1 - Relação dos Meteoritos Brasileiros reconhecidos oficialmente até 2009. (Q) Queda, (A) Achado.

\begin{tabular}{|c|c|c|c|c|c|c|c|}
\hline Tipo & Fato & Nome & Ano & UF & $\begin{array}{c}\text { Grupo } \\
\text { Estrutural }\end{array}$ & $\begin{array}{c}\text { Grupo } \\
\text { Químico }\end{array}$ & $\begin{array}{c}\text { Massa } \\
(\mathrm{Kg})\end{array}$ \\
\hline \multirow{29}{*}{ Férreo } & $\mathrm{A}$ & Angra dos Reis II & $?$ & RJ & Hexaedrito & & \\
\hline & $\mathrm{A}$ & Balsas & 1974 & MA & $\mathrm{Om}$ & IIIAB & 41,00 \\
\hline & $\mathrm{A}$ & Barbacena & 1918 & MG & Of & Anômalo & 9,00 \\
\hline & $\mathrm{A}$ & Bendegó & 1784 & $\mathrm{BA}$ & $\mathrm{Og}$ & $\mathrm{IC}$ & 5360,00 \\
\hline & $\mathrm{A}$ & Blumenau & 1986 & $\mathrm{SC}$ & Of & IVA & $? ? ?$ \\
\hline & $\mathrm{A}$ & Bocaiúva & 1961 & $\mathrm{MG}$ & Ataxito & Anômalo & 64,00 \\
\hline & $\mathrm{A}$ & Casemiro de Abreu & 1947 & RJ & $\mathrm{Om}$ & IIIAB & 24,00 \\
\hline & $\mathrm{A}$ & Crateús (1931) & 1914 & $\mathrm{CE}$ & Of & IVA & 27,50 \\
\hline & $\mathrm{A}$ & Crateús (1950) & 1909 & $\mathrm{CE}$ & Opl & IIC & 0,35 \\
\hline & $\mathrm{A}$ & Indianapólis & 1989 & $\mathrm{MG}$ & Ogg & IIAB & 14,85 \\
\hline & $\mathrm{A}$ & Itapuranga & 1977 & $\mathrm{GO}$ & $\mathrm{Og}$ & IAB & 628,00 \\
\hline & $\mathrm{A}$ & Itutinga & 1947 & MG & $\mathrm{Om}$ & IIIAB & 3,20 \\
\hline & $\mathrm{A}$ & Maria da Fé & 1982 & $\mathrm{MG}$ & Of & IVA & 18,00 \\
\hline & $\mathrm{A}$ & Nova Petropólis & 1967 & $\mathrm{RS}$ & Om & IIIAB & 305,00 \\
\hline & $\mathrm{A}$ & Palmas de Monte Alto & 1954 & $\mathrm{BA}$ & Om & IIIAB & 97,00 \\
\hline & $\mathrm{A}$ & Pará de Minas & 1934 & MG & Of & IVA & 116,30 \\
\hline & $\mathrm{A}$ & Paracutu & 1980 & $\mathrm{MG}$ & $\mathrm{Og}$ & IAB & \\
\hline & $\mathrm{A}$ & Patos de Minas I & 1925 & MG & Hexaedrito & IIAB & 32,00 \\
\hline & $\mathrm{A}$ & Patos de Minas II & 1925 & MG & Octaedrito & IAB & 200,00 \\
\hline & $\mathrm{A}$ & Piedade do Bagre & 1922 & MG & $\mathrm{Om}$ & Anômalo & 59,00 \\
\hline & $\mathrm{A}$ & Pirapora & 1950 & MG & Hexaedrito & IIAB & 8,70 \\
\hline & $\mathrm{A}$ & Sanclerlândia & 1971 & $\mathrm{GO}$ & $\mathrm{Om}$ & IIIAB & 276,00 \\
\hline & $\mathrm{A}$ & Santa Catarina & 1875 & $\mathrm{SC}$ & Ataxito & IAB & 7000,00 \\
\hline & $\mathrm{A}$ & Santa Luzia de Goiás & 1925 & GO & $\mathrm{Og}$ & IIAB & 1920,00 \\
\hline & $\mathrm{A}$ & São João Nepomuceno & $?$ & $\mathrm{MG}$ & Of & IVA & 6,67 \\
\hline & $\mathrm{A}$ & Soledade & 1982 & $\mathrm{RS}$ & $\mathrm{Og}$ & IAB & 68,00 \\
\hline & $\mathrm{A}$ & Uruaçu & 1986 & $\mathrm{GO}$ & Hexaedrito & IAB & 72,00 \\
\hline & $\mathrm{A}$ & Veríssimo & 1965 & $\mathrm{GO}$ & $\mathrm{Om}$ & IIIAB & \\
\hline & $\mathrm{A}$ & Vitória da Conquista & 2007 & $\mathrm{BA}$ & Of & IVA & 10,50 \\
\hline $\begin{array}{c}\text { Férreo- } \\
\text { Petreo } \\
\end{array}$ & A & Quijingue & 1963 & $\mathrm{BA}$ & Palasito & Principal & 59,00 \\
\hline \multirow{4}{*}{$\begin{array}{c}\text { Pétreo- } \\
\text { Acondrito }\end{array}$} & Q & Angra dos Reis & 1869 & RJ & & Angrito & 1,50 \\
\hline & $\mathrm{A}$ & Governador Valadares & 1958 & MG & & Nakhlito & 0,16 \\
\hline & Q & Ibitira & 1957 & $\mathrm{MG}$ & & Eucrito & 2,50 \\
\hline & $\mathrm{Q}$ & Serra de Magé & 1923 & $\mathrm{PE}$ & & Eucrito & 1,30 \\
\hline \multirow{23}{*}{$\begin{array}{c}\text { Pétreo- } \\
\text { Condrito }\end{array}$} & $\mathrm{Q}$ & Avanhadava & 1952 & SP & & H4 & 9,33 \\
\hline & Q & Campos Sales & 1991 & $\mathrm{CE}$ & & L5 & 23,68 \\
\hline & $\mathrm{Q}$ & Conquista & 1965 & MG & & $\mathrm{H} 4$ & 20,35 \\
\hline & $\mathrm{Q}$ & Iguaraçu & 1977 & PR & & $\mathrm{H} 5$ & 1,20 \\
\hline & $\mathrm{Q}$ & Ipiranga & 1972 & $\mathrm{PR}$ & & $\mathrm{H} 6$ & 2,65 \\
\hline & $\mathrm{A}$ & Ipitinga & 1989 & PA & & $\mathrm{H} 5$ & 7,00 \\
\hline & $\mathrm{Q}$ & Itapicuru-Mirim & 1879 & MA & & $\mathrm{H} 5$ & 2,00 \\
\hline & Q & Macau & 1836 & $\mathrm{RN}$ & & $\mathrm{H} 5$ & 36,30 \\
\hline & $\mathrm{Q}$ & Mafra & 1941 & $\mathrm{SC}$ & & L3-L4 & 0,60 \\
\hline & Q & Marília & 1971 & SP & & $\mathrm{H} 4$ & 2,50 \\
\hline & $\mathrm{A}$ & Minas Gerais & 1888 & MG & & L6 & 1,20 \\
\hline & $\mathrm{A}$ & Morro do Roccio & 1928 & $\mathrm{SC}$ & & $\mathrm{H} 5$ & 0,47 \\
\hline & $\mathrm{Q}$ & Parambu & 1964 & $\mathrm{CE}$ & & LL5 & 0,60 \\
\hline & Q & Paranaíba & 1956 & MT & & L6 & 100,00 \\
\hline & $\mathrm{Q}$ & Patrimônio & 1950 & MG & & L6 & 1,80 \\
\hline & $\mathrm{Q}$ & Putinga & 1937 & RS & & L6 & 200,00 \\
\hline & $\mathrm{A}$ & Rio do Pires & $19 ? ?$ & $\mathrm{BA}$ & & L6 & 0,12 \\
\hline & $\mathrm{Q}$ & Rio Negro & 1934 & PR & & L4 & 1,30 \\
\hline & $\mathrm{Q}$ & Santa Bárbara & 1873 & RS & & L4 & 0,40 \\
\hline & Q & Santa Vitória do Palmar & 2003 & RS & & L3 & 63,00 \\
\hline & $\mathrm{Q}$ & São José do Rio Preto & 1962 & SP & & $\mathrm{H} 4$ & 0,93 \\
\hline & $\mathrm{Q}$ & Sete Lagoas & 1908 & $\mathrm{MG}$ & & $\mathrm{H} 4$ & 0,06 \\
\hline & Q & Uberaba & 1903 & MG & & $\mathrm{H} 5$ & 30,00 \\
\hline
\end{tabular}


XIX (Howard 1802), sendo necessárias mais seis décadas até o estabelecimento da primeira classificação estrutural baseada na textura e características físicas a partir de estudos petrográficos (Reichenback 1857 , Story-Maskelyne 1863a, 1863b, Rose 1864), os quais culminaram com a aceitação da origem espacial destas rochas.

O meteorito Bendegó representou papel relevante nesta jornada pelo reconhecimento da meteorítica como ciência. Em 1811, o cidadão inglês Aristides Franklin Mornay (Mornay 1816) foi o primeiro a suspeitar que esta colossal massa de ferro e níquel tinha origem meteorítica. A discussão de sua natureza extra telúrica despertou a atenção de importantes cientistas da época que visitaram o local do achado, destacando-se os austríacos Spix e Martius que coletaram amostras e descreveram sucintamente o meteorito na década de 1820 (Spix J.B. von, Martius C.E.P. von 1823)

Atualmente, a principal massa do meteorito encontra-se no Museu Nacional, no Rio de Janeiro. Amostras diversas, de vários tamanhos e pesos, obtidas da fatia maior destacada da massa principal em 1888 integram o acervo de pelo menos 29 instituições acadêmicas e museus em todo o mundo (Tab. 2).

Os últimos dados analíticos publicados para o Bendegó remontam à década de 1970. Seu papel relevante na investigação dos grupos genéticos de meteoritos de ferro justifica uma reavaliação de sua petrografia e química à luz dos enormes avanços da geoquímica analítica nos últimos anos, os quais disponibilizaram novas técnicas e análises de alta resolução, mundialmente aplicadas ao estudo de meteoritos. Assim, o principal objetivo deste artigo é reportar informações adicionais sobre a circunstância do seu achado e distribuição de espécimes, em conjunto com dados petrográficos e geoquímicos para o meteorito e rochas do local do impacto e da crosta de óxido de ferro encontrada na face inferior da massa e no solo onde ela repousava desde a sua queda. Adicionalmente objetiva-se divulgar a meteorítica junto à comunidade cientifica brasileira.

A DESCOBERTA E DISTRIBUIÇÃO DE ESPÉCIMES $\mathrm{O}$ achado do meteorito Bendegó ocorreu no ano de 1784, provavelmente no mês de junho, durante o reinado de D. Maria I, a Louca, conforme ofícios enviados pelo governador da Bahia, D. Rodrigo José de Menezes ao Secretário de Estado da Marinha e do Ultramar, Martinho de Mello e Castro (Menezes 1784, 1787) e pelo Capitão-Mor do Itapicuru, Bernardo Carvalho da Cunha, ao referido governador (Cunha 1784, 1786).

A identidade do descobridor do meteorito ainda é objeto de controvérsias: Menezes (1784), Cunha (1784) e Mornay (1816) citam textualmente Bernardino da Mota Botelho como o sertanejo responsável pelo achado. Spix e Martius (Spix J.B. von, Martius C.E.P. von 1823), que estudaram o meteorito ainda no leito do rio Bendegó, em 1819, registram que Domingos da Mota Botelho foi quem descobriu a massa de ferro, quando era rapaz e procurava uma vaca desgarrada. Por último, Carvalho (1888), que chefiou a expedição de remoção do meteorito para o Rio de Janeiro, diz em seu relatório final que foi Joaquim da Mota Botelho quem comunicou ao governador da Bahia a descoberta e acompanhou Mornay em sua visita ao local do achado, em 1811. Os ofícios de Menezes (1784) e Cunha (1784), juntamente com o relato de Mornay (1816), não suportam a afirmativa de Carvalho (1888), apesar desta versão ter prevalecido no registro gravado no pedestal que expõe o meteorito à entrada do Museu Nacional, em detrimento de Bernardino da Mota Botelho, citado em três das cinco fontes históricas sobre o achado. O encontro de Martius e Spix com Domingos da Mota Botelho, segundo esses autores, ocorreu 35 anos após a descoberta do meteorito.

$\mathrm{Na}$ Bahia colonial do século XVIII aquela massa de metal foi inicialmente considerada indício de valiosa jazida de ferro, levando o governador a ordenar seu imediato transporte para Salvador a fim de ser remetida a Portugal, determinando também a realização de prospecção do suposto minério. Essa suposição foi de pronto abandonada logo na primeira tentativa de sua remoção, haja vista a constatação da natureza metálica da massa, "uma aborto da Natureza" segundo o Capitão-Mor encarregado das diligências (Cunha 1784), e à completa ausência de ocorrências mineralizadas de ferro na área circunvizinha ao local onde o meteorito foi encontrado.

Nos dois anos seguintes à descoberta do meteorito houve pelo menos três frustradas tentativas para transportá-lo até a capital da Bahia. Na primeira expedição, o meteorito foi removido de seu sitio original através da força de 30 homens aplicada a quatro alavancas de madeira colocadas sob o bloco (Cunha 1786). O solo onde repousava a massa era "duro e pedregulhento sendo difícil de escavar" e o meteorito não apresentava qualquer semelhança com as rochas do local. Sob o mesmo havia uma camada de óxido de ferro, com mais de $22 \mathrm{~cm}$ de espessura (Cunha 1784). Devido ao grande peso e dimensões, e à falta de meios para içar e transportar uma tão grande massa, ela foi deixada junto ao local onde repousava desde sua queda.

$\mathrm{Na}$ segunda tentativa, o bloco de ferro foi colocado sobre uma carreta puxada por bois que percorreram apenas $180 \mathrm{~m}$, distância entre o local do achado e a margem esquerda do riacho Bendegó. $\mathrm{O}$ acentuado declive da margem do córrego, a falta de equipamentos e de material para construir uma passagem, aliadas à escassez de água e mantimentos, determinaram o encerramento dessa segunda missão (Cunha 1784). Durante a terceira tentativa foi construído um aterro ligando as duas margens do riacho, porém o material utilizado, uma mistura de argila, areia, galhos e folhas de árvore da raquítica vegetação da caatinga, não suportaram o peso da carreta e sua carga, que afundaram na areia do leito do rio (Cunha 1786). Embora o governador da Bahia demonstrasse vivo interesse em mandar o meteorito para Portugal, conforme ofício de 
Tabela 2 - Distribuição das amostras do meteorito Bendegó pelo mundo.

\begin{tabular}{|c|c|c|}
\hline Instituição Hospedeira & Cidade/Estado & País \\
\hline Instituto de Planetologia (Institut für Planetologie) & Munster & Alemanha \\
\hline Instituto Max-Plank de Química (Max-Plank Institut fur Chemie) & Mainz & Alemanha \\
\hline Museu de História Natural (Museum fur Naturkunde) & Berlim & Alemanha \\
\hline $\begin{array}{l}\text { Museu Reino dos Cristais - Coleção Estadual Bávara de Mineralogia (Museum } \\
\text { Reich der Kristalle - Mineralogische Staatssammlung München) }\end{array}$ & Munique & Alemanha \\
\hline Univirsidade de Tübingen (Universität Tübingen) & Tübingen & Alemanha \\
\hline Museu da Prata (Museu de la Plata) & La Plata & Argentina \\
\hline Museu de História Natural (Naturhistoriches Museum) & Viena & Áustria \\
\hline Museu de Ciência e Técnica da Escola de Minas & Ouro Preto, MG & Brasil \\
\hline Museu de Geociências da Universidade de São Paulo & São Paulo, SP & Brasil \\
\hline Museu de Mineralogia Prof. Djalma Guimarães & Belo Horizonte, $\mathrm{MG}$ & Brasil \\
\hline Museu Geológico da Bahia & Salvador, BA & Brasil \\
\hline Museu Nacional & Rio de Janeiro, RJ & Brasil \\
\hline Serviço Geológico do Canadá (Geological Survey of Canada) & Otawa & Canada \\
\hline $\begin{array}{l}\text { Museu Geológico - Universidade Københavns (Geologisk Museum - Københavns } \\
\text { Universitet) }\end{array}$ & Compenhague & Dinamarca \\
\hline Museu Nacional de História Natural (Museum National d'Histoire Naturelle) & Paris & França \\
\hline Museu Húngaro de História Natural (Magyar Természettudományi Múzeum) & Budapeste & Hungria \\
\hline Pesquisa Geológica da India (Geological Survey of India) & Calcutá & Índia \\
\hline Museu de História Natural (Natural History Museum) & Londres & Inglaterra \\
\hline Museu do Observatorio do Vaticano (Vatican Observatory Museum) & Vaticano & Itália \\
\hline Academia de Ciências da Rússia (The Russian Academy of Sciences) & Moscou & Rússia \\
\hline Fundação de Estudos Planetários (Planetary Studies Foundation) & Galena, IL & USA \\
\hline Museu Americano de História Natural (American Museum of Natural History) & New York, NY & USA \\
\hline Museu de História Natural (Field Museum of Natural History) & Chicago, IL & USA \\
\hline Museu Nacional dos Estados Unidos (United States National Museum) & Washington, DC & USA \\
\hline Universidade Cristã do Texas (Texas Christian University) & Fort Worth, TX & USA \\
\hline $\begin{array}{l}\text { Universidade da Califórnia em los Ângeles (University of California at Los } \\
\text { Angeles) }\end{array}$ & Los Angeles, CA & USA \\
\hline Universidade do Novo México (University of New Mexico) & Albuquerque, NM & USA \\
\hline Universidade Estadual do Arizona (Arizona State University) & Tempe, AZ & USA \\
\hline
\end{tabular}

17/02/1787 (Menezes 1787), ele não deixou o Brasil, provavelmente devido à situação política instável reinante em Lisboa na década que antecedeu a invasão francesa de 1807, que forçou a família real a trasladarse para sua colônia na América do Sul (Pedreira e Costa 2008).

Finalmente, em 1887, no final do II Império do Brasil, sob os auspícios da Sociedade de Geografia do Rio de Janeiro, foi organizada uma expedição, sob a chefia de José Carlos de Carvalho, para transportar o meteorito para a sede da corte do Imperador D. Pedro II que pessoalmente havia solicitado esse empreendimento. Os trabalhos de remoção e transporte começaram em 7 de setembro de 1887, quando o meteorito foi colocado sobre peças de madeira no leito do riacho Bendegó para fins de cubagem e medições (Fig.1), e terminaram em 15 de junho de 1888, com a chegada do siderito ao Rio de Janeiro (Carvalho 1888). Carvalho (1928, 1888) e Carvalho (1995) descrevem com detalhes essa exitosa expedição que consumiu 126 dias para percorrer os $119 \mathrm{~km}$ que separam o local do achado do meteorito e a estação ferroviária do povoado de Jacurici, no município de Itiúba, de onde seguiu de trem até Salvador, e daí transportada por navio para a Corte do II Império do Brasil. Em 1887, no local do achado, foi erigido o marco D. Pedro II (Fig.1B), destruído por superticiosos moradores locais, pouco tempo depois do meteorito deixar a região. Existem apenas dois registros de marcos construídos em locais de achados de meteoritos, o do Bendegó, Bahia, Brasil (1887), e o de Krasnojarsk, Sibéria, Rússia, 1980 (McCall et al. 2005).

Desde então a massa principal do meteorito Bendegó, com $5.300 \mathrm{~kg}$, após o corte de uma fatia de 60 

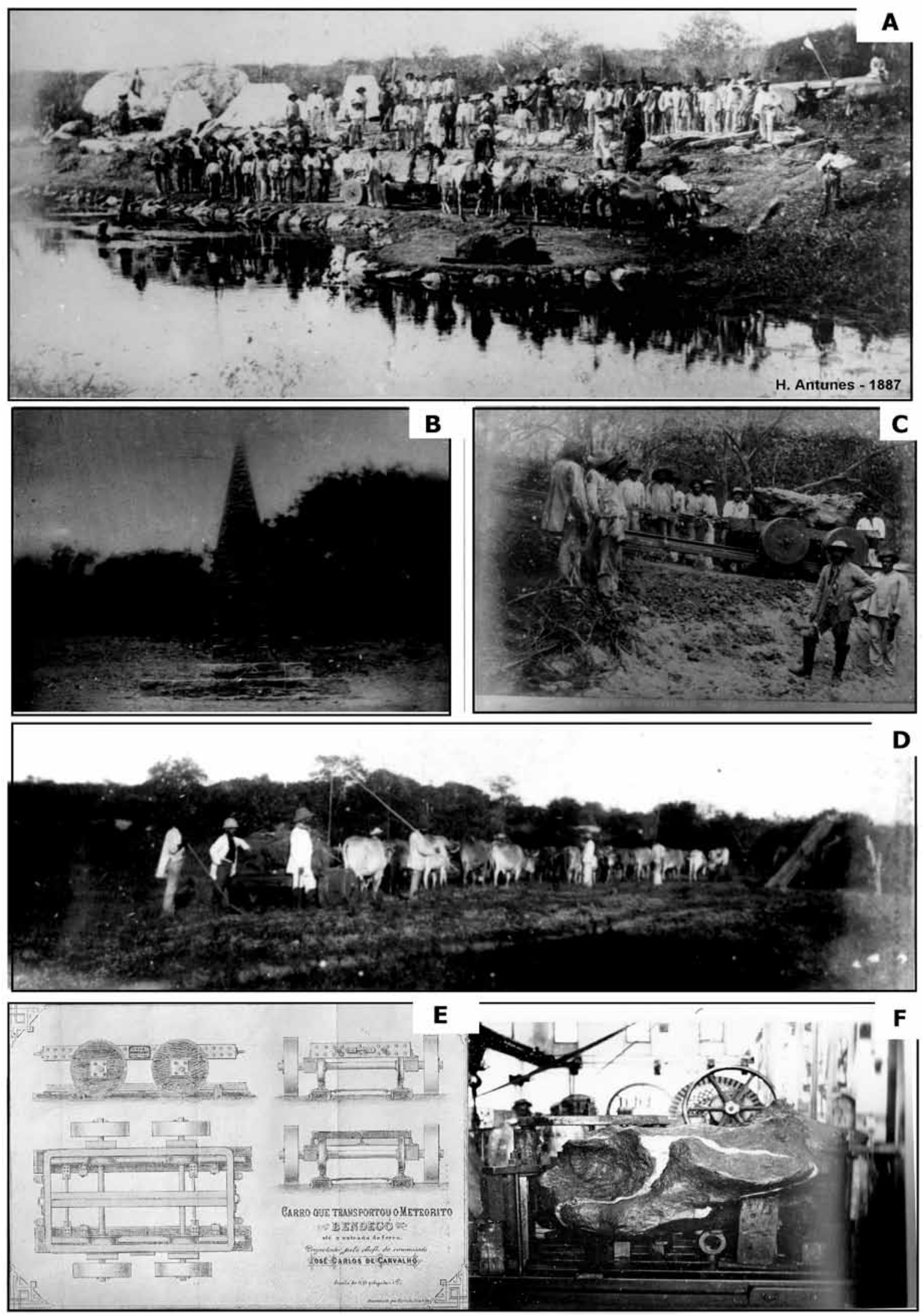

Figura 1 - Fotos históricas da expedição José Carlos de Carvalho, 1887-1888, que transportou o Bendegó da Bahia para o Rio de Janeiro. (A) Dia festivo: remoção do meteorito do leito do Riacho Bendegó, (B) Marco D. Pedro II, erigido no local do achado em 1887, (C) Aterro construído para a passagem do Rio Jacurici, (D) Juntas de bois utilizadas no deslocamento da massa meteorítica, (E) Projeto do carretão que transportou o meteorito, (F) Corte de uma fatia do Bendegó no Arsenal de Marinha - RJ. (Fotos de H. Antunes 1887). 
kg para obtenção de amostras, ocupa lugar de honra à entrada do Museu Nacional (Fig. 2). Quatro réplicas em tamanho natural foram confeccionadas até o presente (2009), uma delas atualmente exposta no museu Palais de la Découvert, em Paris, foi feita em madeira especialmente para a Exposição Universal realizada na capital da França em 1889. As outras três, em gesso e papel-marché, integram o acervo do Museu Geológico da Bahia (Salvador), do Observatório Antares (Feira de Santana) e do Museu do Sertão (Monte Santo), no Estado da Bahia.

\section{ÁREA ESTUDADA: LOCALIZAÇÃO E} ACESSOS O meteorito Bendegó foi achado no sertão baiano, aproximadamente a $250 \mathrm{~km}$ de Salvador. (Fig. 3A e Fig. 3B). Aárea em estudo está compreendida entre as coordenadas E 464.000 - 476.000 e N 8.888 .000 8.872 .000 , formando um retângulo de $12 \mathrm{~km}^{2}$, inserido no semi-árido do Nordeste da Bahia, mais precisamente no território do município de Uauá.

A área estudada está inserida no "Polígono das Secas", uma regiãoárida cuja precipitação pluviométrica situa-se entre 500 e $750 \mathrm{~mm}$ anuais. A vegetação é nativa com predominância de xerófitas (caatinga). A drenagem é do tipo dendrítico, predominando riachos temporários (Inda e al. 1976). O meteorito foi encontrado a 180 metros da margem esquerda do rio Bendegó (Fig. 3). As coordenadas geográficas exatas do local onde o meteorito Bendegó foi achado, conforme levantamento feito pelo Observatório Astronômico Antares, da Universidade Estadual de Feira de Santana, em 2002, são as seguintes: E 471.359,4664 $\left(10^{\circ} 07^{\prime}\right.$ $01,51830 " \mathrm{~S})$ e N 8.881.630,2778 (39 $15^{\circ} 41,12180$ " W). O ponto de referência para se alcançar esse local é o cemitério do povoado Bendegó da Pedra, situado a apenas 200 metros do sítio onde a massa de ferro foi achada em 1784.

MÉTODOS DE TRABALHO Foram realizadas três missões de campo ao local onde o meteorito foi achado (Fig. 4A) para reconhecimento da geologia e coleta de amostras de rochas aflorantes, fragmentos desagregados do embasamento e peças remanescentes do óxido de ferro que originalmente jazia sob a massa metálica (Cunha 1784, Mornay 1816).

Para os estudos petrográficos foram preparadas 14 lâminas delgadas de rochas do embasamento e de fragmentos de anfibólio e de quartzo existentes na superfície do local do achado do meteorito. A metalografia do meteorito foi estudada através de uma lâmina polida preparada a partir de uma amostra cedida pelo Museu Nacional do Rio de Janeiro e que foi
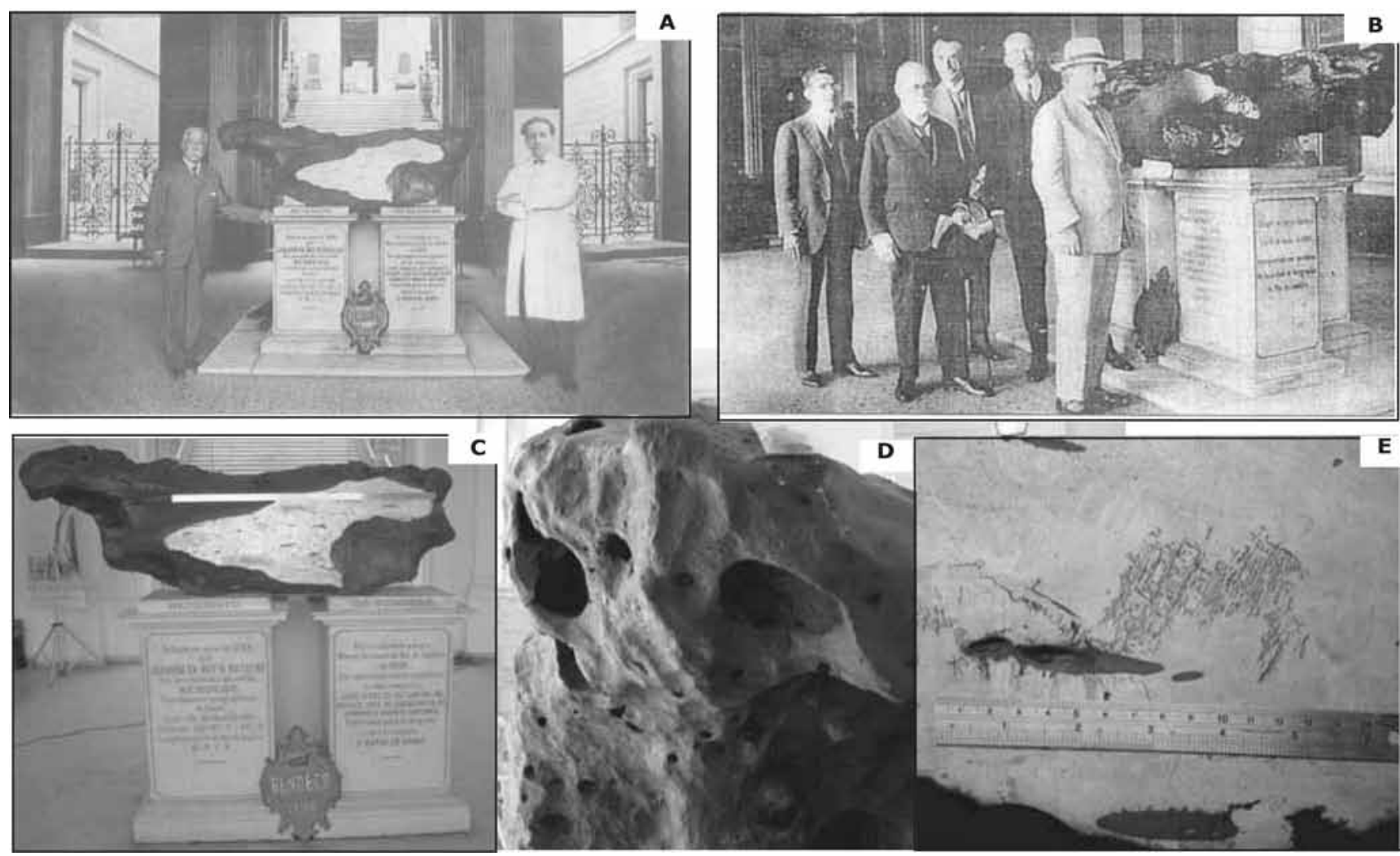

Figura 2 - Fotos do meteorito Bendegó no Museu Nacional, Rio de Janeiro. (A) Sr. José Carlos de Carvalho (à esquerda), chefe da expedição 1887-1888, ao lado do diretor do Museu Nacional Prof. Roquete Pinto, (B) Visita do físico Albert Einstein em 07 de maio de 1925 (postal astronômico, Observatório Nacional/MCT, M. R. Nunes 2002), (C) Visão do meteorito exposto. Detalhes de sua estrutura: (D) Regmalites e cavidades, (E) Coenita e troilita na face cortada e polida. 
(B) MAPA DE ACESSO
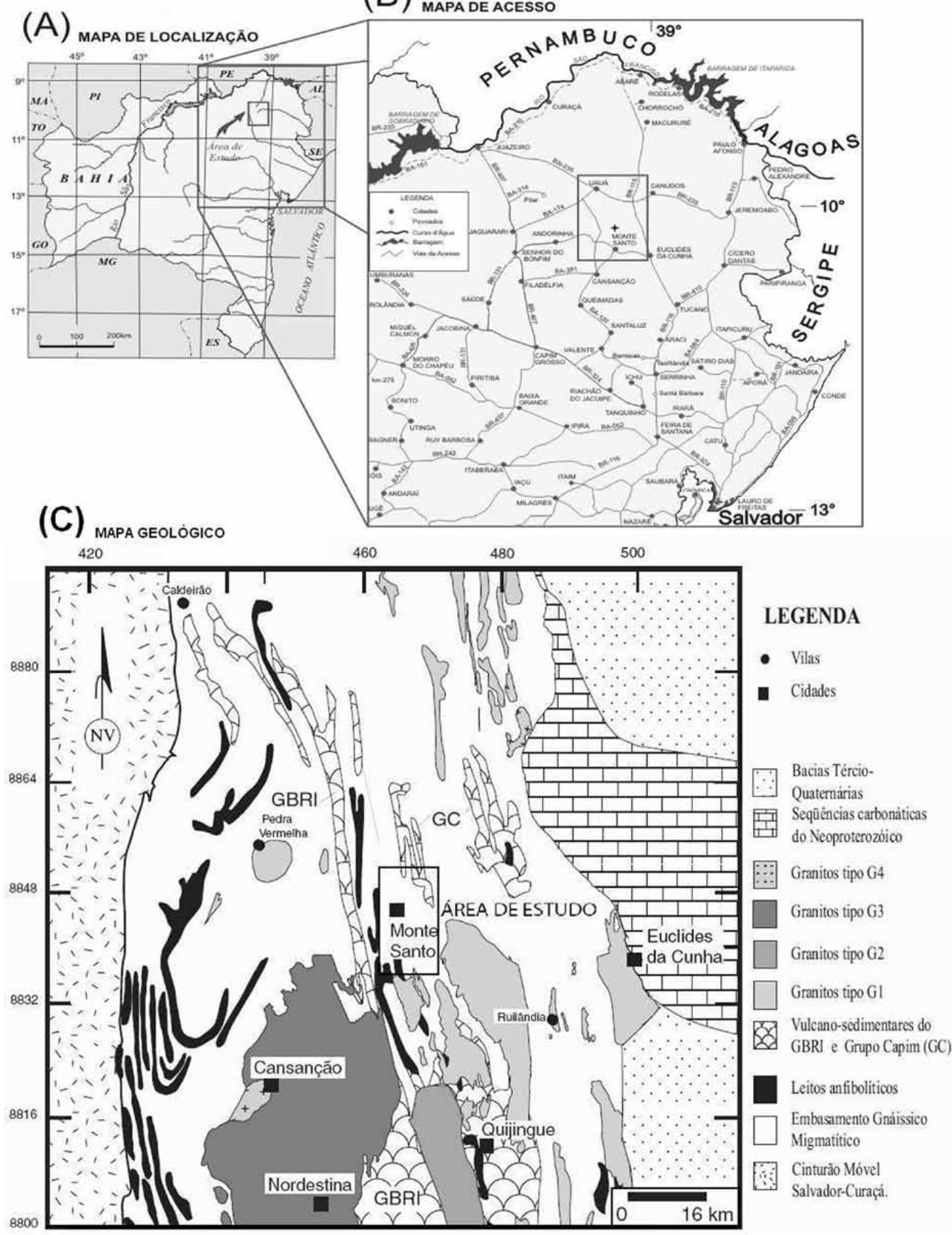

Figura 3 - (A) Mapa de situação do local do achado do Meteorito Bendegó. (B) Mapa de acessos. (C) Mapa geológico simplificado da área de estudo (Após Rios et al. 2009).

analisada através de microscopia de varredura eletrônica (MEV), usando equipamento Shimatzu modelo SSX 550, do Instituto de Química da Universidade Federal da Bahia. Outras duas fatias do meteorito, pertencentes ao acervo do Museu Nacional foram estudadas petrograficamente sob luz refletida.

Os estudos geoquímicos envolveram amostras do meteorito e das rochas encaixantes e do local do achado. Duas amostras do meteorito foram analisadas respectivamente por Espectrometria de Massa 


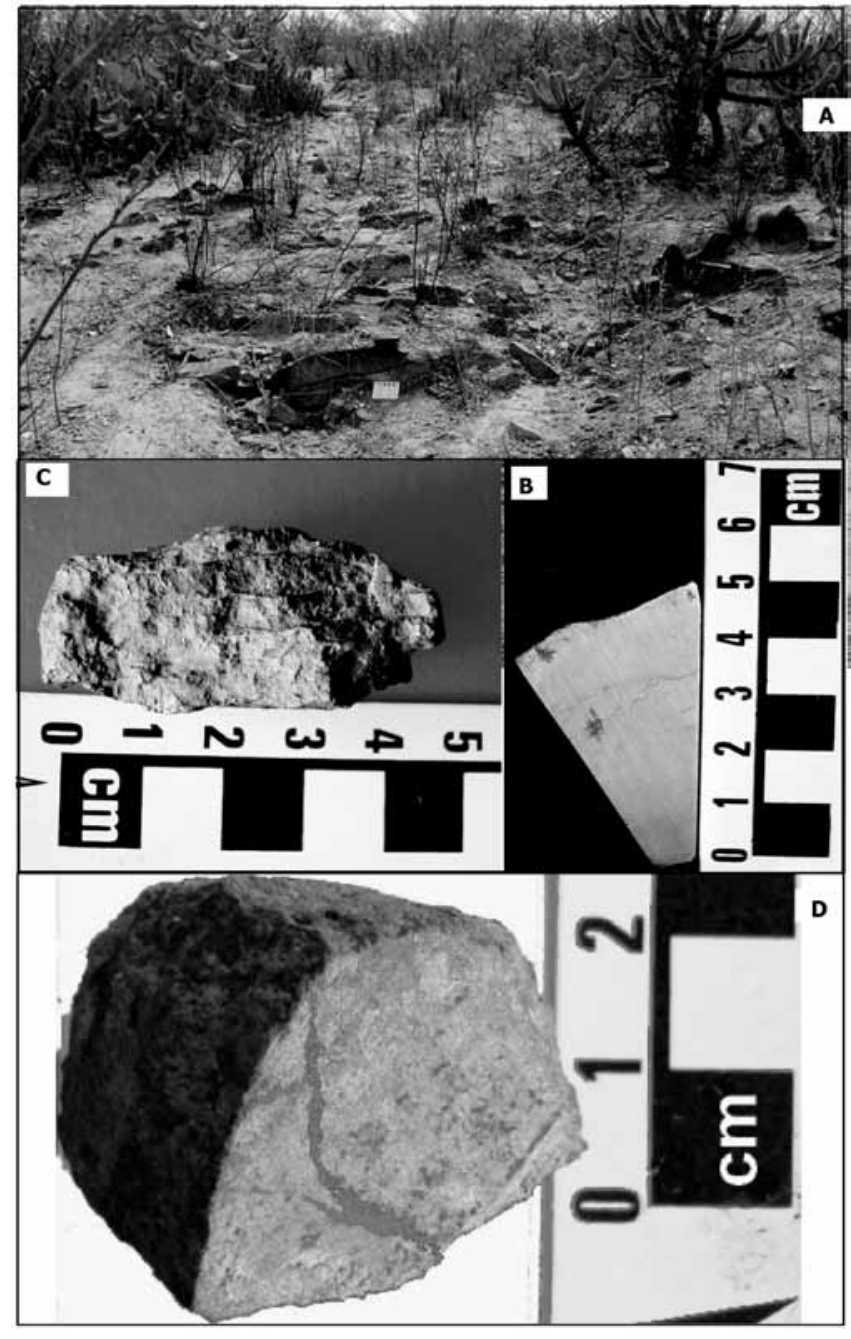

Figura 4 - Fotos das etapas de campo e amostragem. (A) Visão do local do achado original do meteorito Bendegó onde afloram gnaisses e anfibolitos, (B) Fatia do Bendegó enviada para análise por INAA, (C) Fragmento do óxido de ferro, (D) Rocha do embasamento cortada por veios metálicos.

Indutivamente Acoplada a Plasma (ICP-MS) e por Ativação Neutrônica Instrumental (INAA).

ASPECTOS GEOLÓGICOS O local do achado do meteorito Bendegó está situado no Cráton do São Francisco. onde destaca-se um embasamento gnáissico migmatitico intrudido por granitos TTGs. Na área onde o meteorito foi encontrado que se acredita representar também o ponto de impacto o embasamento é formado predominantemente por gnaisses bandados, com xistosidade bem desenvolvida e orientação NNWSSE (Inda et al. 1976, Rios et al. 2009). Para o mapeamento foi limitado um retângulo de $12 \mathrm{~km}^{2}$ (Fig. 3C), coordenadas E 464.000-476.000 e N 8.888.0008.872.000, onde os gnaisses são quartzo-feldspáticos, localmente cataclásticos, com intercalações de rochas básicas e ultrabásicas metamorfizadas e rochas calcossilicatadas. Em menor escala ocorrem hornblenda-gnaisses e hornblenda-biotita-gnaisses com intercalações subordinadas de anfibolito. Inda e colaboradores (1976) descrevem nesta região ocorrências de "diatexitos a biotita homogêneos e não homogêneos, de composição variando de granítica até anfibolítica, englobando porções metatexíticas não transformadas e transformadas anfibolíticas".

Em campo, observam-se inúmeros fragmentos de quartzo leitoso e de anfibolitos na superfície da área que circunda o local do achado, os quais podem ter originalmente constituído veios intrudidos no gnaisse do embasamento, juntamente com anfibolitos, provavelmente desagregados das rochas metamórficas do Complexo Uauá. O relato de Mornay (1816) cita a existência de fragmentos de quartzo leitoso firmemente presos em algumas cavidades da massa de ferro, sendo necessário o uso de martelo e talhadeira para extraí-los. Contudo, o estudo petrográfico realizado em 14 lâminas delgadas de amostras de rochas gnáissicas, fragmentos de quartzo, e anfibolitos, coletados na área estudada, não evidenciam a presença de elementos planares de deformações (PDFs), comumente observados em cristais de quartzo coletados em crateras de impacto. Para formação de estruturas PDFs é necessária uma pressão entre 4 e $50 \mathrm{GPa}$ (Goltrant et al., 1992). Acredita-se que a ocorrência dos fragmentos de quartzo no meteorito sinalize a possibilidade dele ter fragmentado rochas do embasamento ou apreendido seixos existentes na superfície no momento do impacto sem, entretanto, atingir a pressão necessária para produzir as estruturas de PDFs.

\section{MINERALOGIA}

Trabalhos Anteriores O meteorito Bendegó vem sendo estudado desde 1816 quando Wollaston (Wollaston, 1816) apresentou à Sociedade Real de Londres resultados positivos de ensaios químicos para determinação de $\mathrm{Ni}$ em fragmentos metálicos e em amostras oxidadas coletadas por Mornay em 1811. Wollaston notou também a forma octaédrica de alguns dos fragmentos estudados. Segundo Buchwald (1975), no século XIX o meteorito Bendegó foi objeto de estudos e citações por seis autores: Reichenbach (1862), Partsch (1843), Wöhler (1860), Derby (1896), Ward (1892) e Wülfing (1897). No século XX foram publicados trabalhos e fotografias do meteorito por Vidal (1936), Perry (1944) e Curvelo (1958). Esse último apresentou a hipótese do mineral troilita, presente em algumas amostras, ter passado por um processo de exsolução, resultando em dois tipos distintos de estrutura: alfa e beta troilita. Ainda de acordo com Buchwald (1975), Olsen (1964) estudou o Bendegó juntamente com outros meteoritos férreos objetivando determinar a estabilidade do mineral coenita.

$\mathrm{Na}$ década de 1970 e seguintes os meteoritos metálicos foram extensivamente estudados através de instrumentação de alta tecnologia e sofisticados métodos de análise química tais como microssondas e microscópios eletrônicos, ICP-MS e INAA, destacando-se os trabalhos de John Wasson e seus colegas da Universidade da Califórnia em Los Ângeles 
(UCLA), que resultaram na classificação moderna dos meteoritos de ferro (Wasson, 1974; Scott \& Wasson, 1976; Wasson et al. 1998, 2007, Wasson \& Kallemeyn, 2002). Nesta época, o Bendegó figurou entre as seis centenas de meteoritos estudados por esse grupo de cientistas, sendo considerado inicialmente como um espécime anômalo (Wasson, 1974). Posteriormente, ele passou a integrar um novo grupo genético, o IC, que corresponde a um conjunto de 11 meteoritos raros, estudados por Scott (1977).

$\mathrm{O}$ grupo IC de meteoritos pertence à classe dos não-condritos, diferenciados, férreos, conforme a classificação proposta por Krot et al. (2005) para rochas de origem espacial (Fig. 5).

Feições macroscópicas A massa principal do meteorito Bendegó tem 2,15 x 1,50 x 0,66 metros (Fig. 6A). Macroscopicamente foram realizadas observações na face exposta pelo corte efetuado no meteorito em 1888, medindo $1,07 \times 0,42 \mathrm{~m}$ em suas maiores dimensões. Para tanto, foi necessário limpar, polir e submeter a superfície à ação corrosiva do Nital (Fig. $6 \mathrm{~A})$.

Pelo menos 37 ocorrências de troilita são facilmente identificadas a olho nu na grande face polida do corpo principal do meteorito exposto no Museu Nacional. Elas apresentam-se como manchas escuras, alongadas e alinhadas no sentido longitudinal ao grande eixo do meteorito. Outra feição que se destaca macroscopicamente são seis manchas de coenita, de cor ocre, e tendo no interior de sua malha rendada nódulos de troilita (Fig. 6A). Pode-se observar também nessa face polida muitas lamelas de kamacita formando o padrão Widmanstätten (Fig.6A).

Em todo o corpo da massa observam-se numerosas cavidades circulares ou elipsóides, de dimensões e profundidades variáveis, algumas com até $10 \mathrm{~cm}$ de diâmetro (Fig. 6B). Derby (1896) contou 40 cavidades na face superior, 26 na parte posterior e 20 na anterior. Esses furos são conseqüência do processo de ablação durante a passagem do corpo pela atmosfera terrestre, cuja elevada temperatura fundiu e vaporizou a troilita (FeS) e aumentou as dimensões do espaço anteriormente preenchido por esse mineral.

Composição Mineralógica e Estruturas Para as análises por microscopia eletrônica de varredura (SEMEDS), uma fatia poligonal com $21 \times 18 \times 14 \times 13 \mathrm{~mm}$ de tamanho, pesando $2 \mathrm{~g}(6 \mathrm{C}$ ) foi polida com lixa d'água de grana 100 a 600 para remoção das partes alteradas e das marcas de serra, até se obter uma superfície espelhada e uniforme que foi submetida a uma solução a $2 \%$ de $\mathrm{HNO}_{3}$ e $\mathrm{CH}_{3} \mathrm{CH}_{2} \mathrm{OH}$ (Nital) durante 15 minutos e em seguida exagüada em água para interromper o processo de corrosão, resultando desse procedimento o aparecimento do padrão Widmanstätten.

Mais duas amostras pertencentes ao acervo do Museu Nacional, uma com formato triangular, medindo $60 \times 70 \times 70 \mathrm{~mm}$ (Fig. 6D) e outra retangular contendo um nódulo de troilita, com 32x22 mm (Fig. 6E) foram

\section{CLASSIFICAÇÃO QUIIMICA DOS METEORITOS}
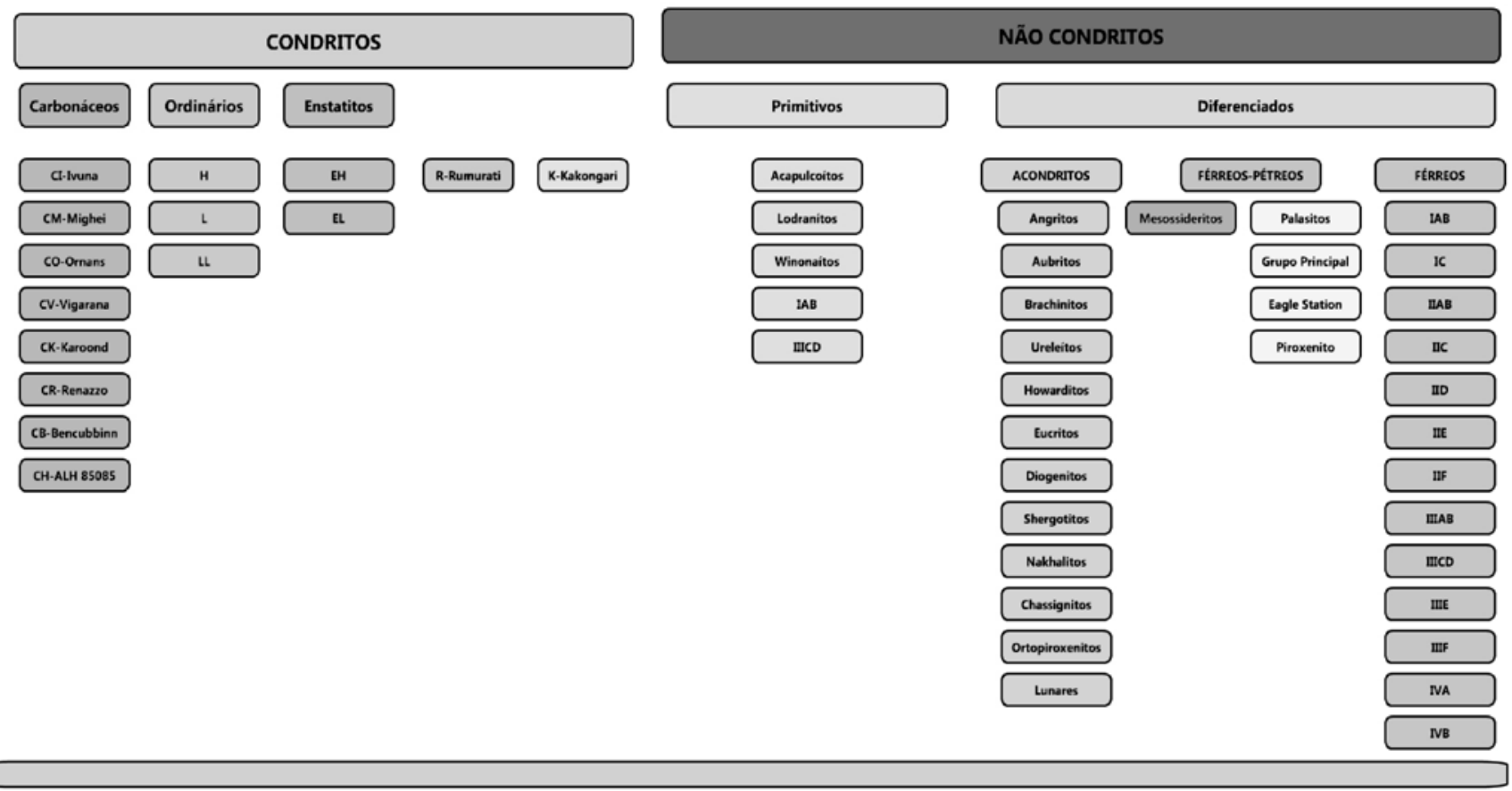

Figura 5 - Classificação química dos meteoritos, segundo proposta de Krot et al. (2005). Traduzida e adaptada. 

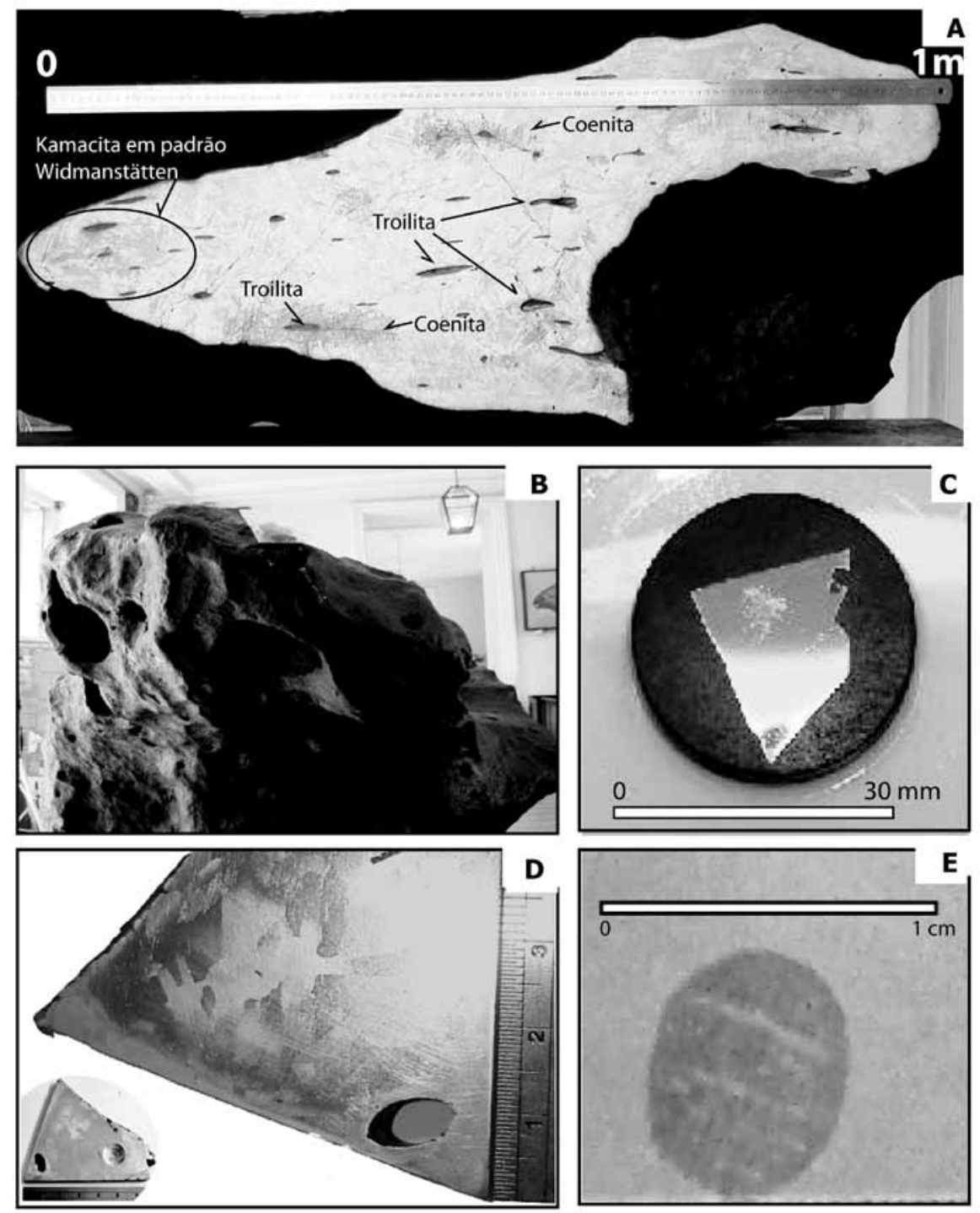

Figura 6 - Fotos das amostras trabalhadas para a descrição petrográfica macro e microscópica do Bendegó. Massa principal exposta no Museu Nacional: (A) face polida mostrando ocorrências de troilita, coenita e kamacita com padrão Widmanstätten e (B) Face anterior (bico) com cavidades de dimensões e profundidades variadas, resultado da ablação da troilita. Amostras cedidas pelo Museu Nacional, polidas e atacadas por nital para estudos petrográficos: (C) Lâmina para microscopia eletrônica de varredura, (D) amostra triangular, (E) nódulo de troilita.

preparadas utilizando-se o mesmo método acima descrito, sendo destinadas ao estudo da metalografia do meteorito através de microscopia petrográfica.

A kamacita, uma liga $\alpha$ de $\mathrm{Fe}-\mathrm{Ni}$, é volumetricamente a fase mineralógica predominante no Bendegó, correspondendo a mais de $2 / 3$ de seu volume. Apresenta-se em lamelas com largura média de 1,8 mm (Fig. 7A).

Em abundância, o segundo mineral mais importante na massa do Bendegó é a taenita (Fig. 7B), uma liga $\beta$ de $\mathrm{Fe}-\mathrm{Ni}$, semelhante à kamacita, porém com maior teor de Ni. Na amostra estudada a taenita ocorre como finíssimas lamelas (5 a $19 \mu \mathrm{m}$ de largura), dispostas entre as placas de kamacita (Fig. 7A), ao redor de nódulos de troilita, ou circundando manchas de coenita.

O restante da massa é representado por uma mistura granular de kamacita e taenita, em forma acicular, conhecida como plesssita e numerosos nódulos de troilita (FeS). A assembléia de fases presentes neste meteorito inclui ainda schreibersita e rabdita (Fig. 7C), polimorfos de $\left((\mathrm{Fe}, \mathrm{Ni})_{3} \mathrm{P}\right)$, encontradas comumente associadas com coenita $\left((\mathrm{Fe}, \mathrm{Ni}, \mathrm{Co})_{3} \mathrm{C}\right)$, cromita $\left(\mathrm{FeCr}_{2} \mathrm{O}_{4}\right)$. A bibliografia descreve ainda a presença do carboneto hexonita $\left(\mathrm{Fe}_{(2,3)} \mathrm{C} 6\right)$ no meteorito Bendegó, contudo este mineral não foi observado na amostra deste estudo. Estes dados estão de acordo com os estudos prévios realizados por Derby (1896), Buchwald 

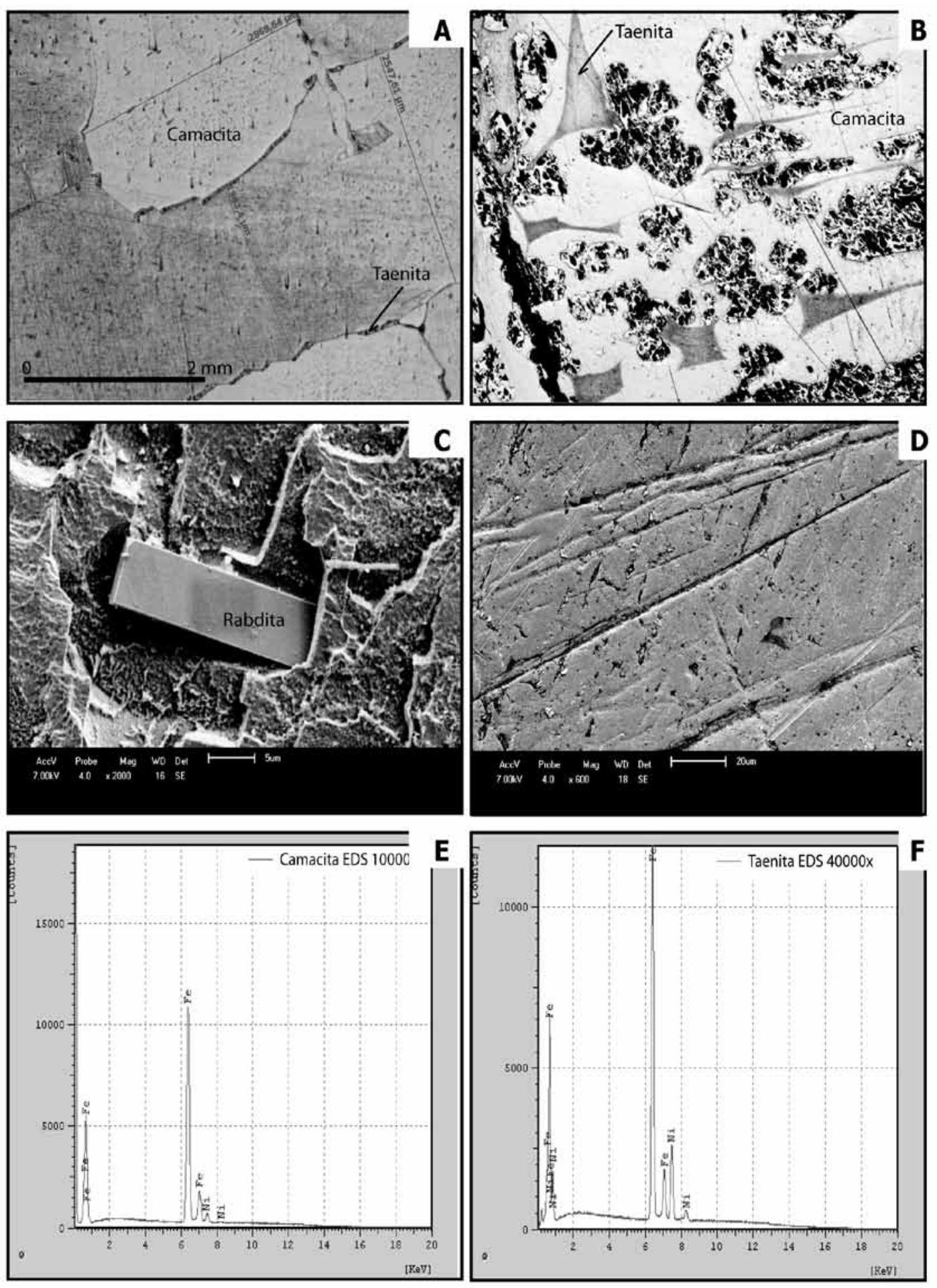

Figura 7 - Microfotografias do meteorito Bendegó: (A) Cristais de kamacita, e taenita dispostas nos contatos. (B) Cristais de taenita, inclusos na kamacita. (C) Cristal de rabdita, tabular, incluso na kamacita (MEV). (D) Linhas de Neumman (MEV). (E) Gráfico EDS da kamacita. (F) Gráfico EDS da taenita, mostrando os maiores teores de Ni, quando relacionados com a kamacita.

(1975), e Scott (1977).

As linhas de Neumman são resultado de deformações mecânicas que ocorrem a baixas tempertauras, abaixo dos $600^{\circ} \mathrm{C}$ (Mason 1962). Na amostra estudada estas linhas estão bem definidas (Fig.
7D). Os estudos de microscopia eletrônica permitiram ainda distinguir a posição dos elementos $\mathrm{Ni}$ e $\mathrm{Fe}$ nas estruturas cristalográficas da kamacita (Fig. 7E) e taenita (Fig. 7F), demonstrando o enriquecimento em $\mathrm{Ni}$, e a substituição do Fe por este elemento na estrutura 
cristalográfica da kamacita, levando à formação da taenita.

\section{COMPOSIÇÃO QUÍMICA E CLASSIFICAÇÃO Análises por Espectrometria de Massa com Plasma Inductivamente Acoplado (ICP-MS) As análises} por ICP-MS foram realizadas no Dipartimento di Scienze della Terra da Universitá de Pisa, Itália, utilizando a metodologia proposta por D'Orazio e Folco (2003). O equipamento utilizado foi um Thermo PQ II Plus ICP-MS instalado em laboratório limpo classe 10000. Duas alíquotas de $245,44 \mathrm{mg}$ (A) e 201,54 mg (B) foram cortadas a partir de uma amostra do meteorito Bendegó com 4,133 g, e polidas com papel abrasivo de $\mathrm{SiC}$ (400 mesh). Ambas foram repetidamente lavadas em banho ultrasônico com água ultrapura (Milli-Q, 18.2 MW cm) e acetona, e secas em estufa. A alíquota (A) foi dissolvida em $4 \mathrm{ml}$ de aqua regia a aproximadamente $80^{\circ} \mathrm{C}$, enquanto a alíquota B foi dissolvida em $5 \mathrm{ml} \mathrm{HNO}, 6 \mathrm{~N}$ a cerca de $80^{\circ} \mathrm{C}$. Dois brancos foram preparados junto com as amostras do meteorito. Ao final da dissolução, as amostras foram transferidas para frascos de vidro de $20 \mathrm{ml}$. A aliquota (A) foi usada para determinação de $\mathrm{Ru}, \mathrm{Rh}, \mathrm{Pd}, \mathrm{Sn}, \mathrm{Sb}$, W, Re, Ir, Pt e Au, enquanto a alíquota "B" foi utilizada para determinar $\mathrm{Ni}, \mathrm{Co}, \mathrm{Cu}, \mathrm{Ga}$, Ge e Mo.

Os elementos traços foram determinados usando o método de adição padrão. Este método consiste em tomar duas sub-amostras iguais de cada solução e adicionar a uma delas quantidades conhecidas de cada analito (tomados a partir de $10 \mu \mathrm{g} / \mathrm{ml}$ de soluções padrão mono-elemental, CPI International, USA). A sensibilidade de cada analito é então obtida medindo as sub-amostras com e sem a adição. Este método tem acuracidade melhor em relação ao metodo de calibração externa porque ele eficientemente reduz os efeitos de matriz.

As massas analíticas utilizadas foram as seguintes: ${ }^{60} \mathrm{Ni},{ }^{59} \mathrm{Co},{ }^{65} \mathrm{Cu},{ }^{69} \mathrm{Ga},{ }^{74} \mathrm{Ge},{ }^{95} \mathrm{Mo},{ }^{101} \mathrm{Ru}$, ${ }^{103} \mathrm{Rh},{ }^{105} \mathrm{Pd},{ }^{118} \mathrm{Sn},{ }^{121} \mathrm{Sb},{ }^{182} \mathrm{~W},{ }^{185} \mathrm{Re},{ }^{193} \mathrm{Ir},{ }^{195} \mathrm{Pt},{ }^{197} \mathrm{Au}$. As medidas foram corrigida para a contribuição do branco, padrão interno $\left({ }^{85} \mathrm{Rb}\right.$ e $\left.{ }^{232} \mathrm{Th}\right)$ e interferências isobáricas $\left({ }^{58} \mathrm{Fe}^{16} \mathrm{O},{ }^{58} \mathrm{Ni}^{16} \mathrm{O} \mathrm{e}{ }^{57} \mathrm{Fe}^{16} \mathrm{O}^{1} \mathrm{H}\right.$ para $\left.{ }^{74} \mathrm{Ge}\right)$. Ni e Co foram determinados diluindo 2000 -vezes a solução (B), e calibrando com uma solução sintética de 1000 $\mathrm{ng} / \mathrm{ml} \mathrm{Ni}-100 \mathrm{ng} / \mathrm{ml} \mathrm{Co}$. A precisão analitica é melhor que $10 \%$ RSD para os elementos cuja concentração é $>$ $1 \mu \mathrm{g} / \mathrm{g}$ e significantemente maior para elementos cujas concentrações estejam próximas do limite de detecção ( $\mathrm{Sb}$ e $\mathrm{Re})$.

Análises por Ativação Instrumental de Nêutrons (INAA) As análises por INAA utilizaram o Reator Nuclear McMaster, do Becquerel Laboratório (Ontário, Canadá), adotando-se a técnica de "contagem" da amostra irradiada, segundo metodologia de rotina naquele laboratório.

Para determinação de $\mathrm{Cr}, \mathrm{Co}, \mathrm{Ni}, \mathrm{As}, \mathrm{W}, \mathrm{Ir}, \mathrm{Au}$, $\mathrm{Sb}$, Mo e Re foi utilizada uma amostra (C) do meteorito com 15 gramas (Fig. 4B), medindo $50 \mathrm{~mm}$ no seu maior comprimento, selada em saco plástico com $2 \mathrm{~mm}$ de espessura e submetida a irradiação por um fluxo de nêutrons de $8 \times 10^{12} \mathrm{n} / \mathrm{cm}^{2} / \mathrm{s}^{-1}$ durante 20 minutos. Foram realizadas duas contagens sendo a primeira após seis dias, e a segunda após transcorridos 20 dias da irradiação. A precisão analítica desse procedimento para $\mathrm{Co}, \mathrm{Au}, \mathrm{Fe}, \mathrm{Ni}$ é de aproximadamente $3 \%$ do Desvio Padrão Relativo (RSD) e para o $\mathrm{As}, \mathrm{Cr}$, Ir e W situa-se entre 7 e $10 \%$ RSD.

Para determinação dos elementos $\mathrm{Pt}, \mathrm{Pd}, \mathrm{Rh}$, $\mathrm{Ru}$ uma alíquota da amostra foi fundida em mufla, para concentrar esses elementos em um "botão de sulfeto de níquel" que foi pulverizado em seguida e tratado com ácido, resultando em precipitados que foram irradiados duas vezes por um fluxo de nêutrons de $8 \times 10^{12} \mathrm{n} / \mathrm{cm}^{2} / \mathrm{s}^{-1}$ durante 20 minutos e submetidos a três contagens. Para as amostras dosadas por INAA, os elementos $\mathrm{Cu}, \mathrm{Ga}$, $\mathrm{Ge}, \mathrm{In}, \mathrm{Sn}$ e $\mathrm{S}$ foram analisados no ACME Laboratórios (Canadá) por ICP-MS segundo o método tradicional de digestão em ácidos fortes.

Adicionalmente analisou-se por INAA (i) uma amostra do óxido de ferro, proveniente da massa principal do siderito enquanto ela permaneceu no local da queda (Fig. 4C), (ii) uma amostra de rocha do embasamento da região coletada na superfície do local do achado e que apresenta um veio com conteúdo metálico (Fig. 4D), e (iii) o material deste veio metálico. Para essas amostras foram determinados e dosados $\mathrm{Cr}$, $\mathrm{Co}, \mathrm{Ni}, \mathrm{As}, \mathrm{W}, \mathrm{Ir}, \mathrm{Au}, \mathrm{Sb}, \mathrm{Mo}$ e Re.

Classificação Química Meteoritos férreos são classificados basicamente em função de sua composição química, utilizando-se para isto diagramas comparativos das concentrações de $\mathrm{Ni}$ em relação a elementos químicos típicos como $\mathrm{Ga}, \mathrm{Ge}, \mathrm{Au}, \mathrm{As}$ e Ir (Fig. 8). O grupo IC de meteoritos férreos foi individualizado na década de 70 (Scott e Wasson 1976), sendo caracterizado por teores de Níquel variando de 6,1 a $6,9 \%$ (Tab. 3). Este grupo ainda é muito pouco estudado e inclui o meteorito Bendegó e mais dez espécimes (Tab. 3, Scott 1977, Kracher et al. 1980).

Tais diagramas geoquímicos clássicos permitem situar amostras do grupo IC entre o IAB e IIAB, constituindo uma classe à parte (Scott 1977). Nota-se nestes diagramas algumas dispersões e superposições, como é o caso do Ga, em que o campo dos IC superpõese ao campo referentes aos meteoritos do grupo IIAB. As linhas de tendência encontradas para as concentrações de outros elementos-traço ( $\mathrm{Au}, \mathrm{Ir}, \mathrm{As})$ demonstram uma boa correlação, resolvendo este tipo de conflito. Foram as análises destes elementos que permitiram a Scott (1977) individualizar meteoritos anteriormente considerados anômalos no grupo IC (Tab. 3).

As novas análises realizadas em duas amostras do meteorito Bendegó pelas metodologias INAA e ICP MS resultaram em teores com variações diminutas para os elementos analisados, quer se comparadas entre si, quer em relação à análise apresentada por Scott (1977), tabela 4. Essas variações devem-se às diferentes metodologias aplicadas e às inovações tecnológicas 

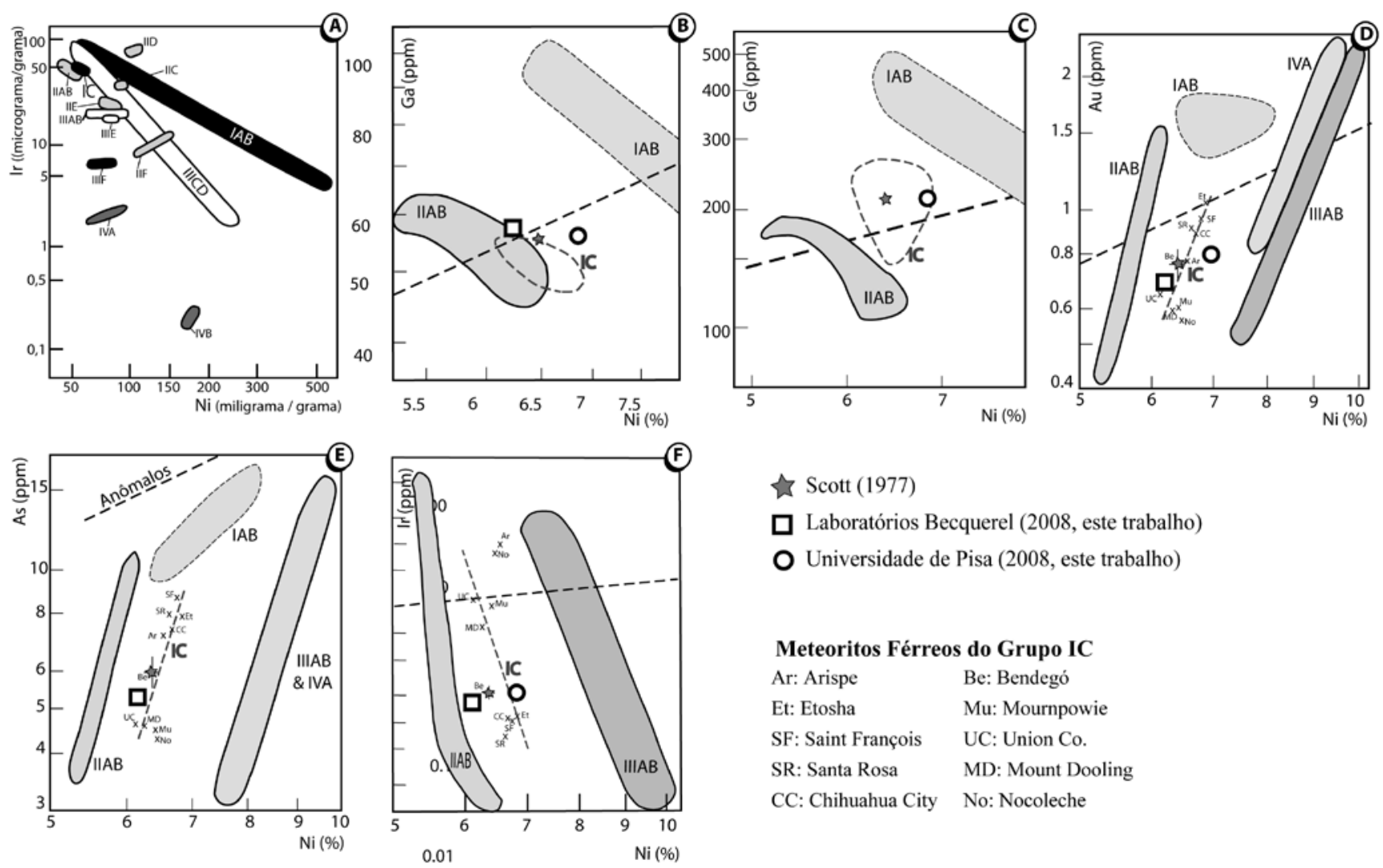

Figura 8 - Diagramas, em escala logaritimica, para classificação química dos meteoritos férreos, apresentando novos dados químicos para o meteorito Bendegó. (A) Diagrama Ir versus Ni, para os grupos de Wasson (1974). (B) Diagrama Ga versus Ni, distinguindo o grupo IC do IAB e IIAB. (C) Diagrama Ge versus $\mathrm{Ni}$, resolvendo a superposição dos grupos IC e IIAB. (D) Diagrama Au versus Ni, mostrando a correlação positiva do grupo IC. (E) Diagrama As versus Ni, distinguindo o grupo IC dos anômalos. (F) Diagrama Ir versus Ni, para o grupo IC, IIAB e IIIAB, apresentando a distinção entre estes grupos. Áreas definidas por Scott (1977).

dos equipamentos utilizados em 2009 pelos autores e na década de 1970 por Scott cuja precisão analítica e níveis de erro admitidos não são idênticos. Deve-se levar em conta ainda que as três análises comparadas na tabela 4 foram feitas em amostras distintas extraídas de diferentes partes da massa principal que podem refletir heterogeneidades existentes no corpo do meteorito.

Os teores encontrados para $\mathrm{Ni}, \mathrm{Ga}, \mathrm{Ge}$ e Ir, bem como as concentrações de outros elementos traços como $\mathrm{Co}, \mathrm{W}, \mathrm{Sb}, \mathrm{Au}$ e As são consistentes com o grupo IC. Observa-se que, apesar das variações entre as diferentes amostras estudadas, e considerando-se as diferentes metodologias aplicadas, não ocorrem superposições com membros de outros grupos (Fig. 8).

Os dados apresentados demonstram que Bendegó é química e estruturalmente muito similar à maioria dos meteoritos do grupo IC, sendo o membro deste grupo que possui a maior massa. Os novos dados para Ni (Tab. 4) apresentam uma variação que cobre toda a gama possível para os membros deste grupo (Tabela 3). Quando os dados disponíveis para o Bendegó (Tab. 4) são confrontados com os outros membros do grupo IC (Tab. 3), percebe-se que Bendegó apresenta teores intermediários de $\mathrm{Ge}$, Au e As, e o maior valor para o $\mathrm{Ga}(54-56 \mathrm{ppm})$, associados a baixos teores de $\operatorname{Ir}(0,17$ a $0,22 \mathrm{mg} / \mathrm{g}$ ).

As concentrações de As e de Au do Bendegó apresentam uma dispersão significativa em relação aos demais membros do grupo IC, os quais dispõem-se ao longo de uma linha no diagrama Ni versus $\mathrm{Au}$ (Fig. 8D) e Ni versus As (Fig. 8E), respectivamente. Contudo, os novos dados obtidos neste estudo ratificam este comportamento, demonstrando que em relação a estes elementos há uma diferença visível do Bendegó para os outros membros do grupo IC.

As análises efetuadas confirmam ainda a eficácia do método proposto por D'Orazzio e Folco (2003) para a análise química de meteoritos, tendo sido encontrados valores compatíveis com os publicados por Scott (1977) e com os realizados pela metodologia clássica de INAA no laboratório Becquerel (este trabalho), para todos os elementos.

Os resultados obtidos pela metodologia INAA aplicada a um fragmento de óxido de ferro proveniente do local do achado do meteorito Bendegó (Fig. 8C, Tab. 4) sugerem uma origem meteorítica, haja vista 
Tabela 3 - Análises geoquímicas para os meteoritos férreos do grupo IC (dados de Wasson 1974; Scott e Wasson 1976; Scott 1977, Kracher et al. 1980). As análises estão apresentadas em ordem crescente do teor de níquel.

\begin{tabular}{l|c|c|c|c|c|c|c|c|c|c|c}
\hline Meteorito & Sigla & $\begin{array}{c}\text { Local do } \\
\text { Achado }\end{array}$ & $\begin{array}{c}\text { Massa } \\
(\mathbf{K g})\end{array}$ & $\begin{array}{c}\mathbf{N i} \\
\mathbf{( \% )}\end{array}$ & $\begin{array}{c}\mathbf{G a} \\
(\mathrm{mg} / \mathbf{g})\end{array}$ & $\begin{array}{c}\mathbf{G e} \\
(\mathrm{mg} / \mathbf{g})\end{array}$ & $\begin{array}{c}\mathbf{I r} \\
(\mathrm{mg} / \mathbf{g})\end{array}$ & $\begin{array}{c}\mathbf{A u} \\
(\mathrm{mg} / \mathbf{g})\end{array}$ & $\begin{array}{c}\mathbf{A s} \\
(\mathbf{m g} / \mathbf{g})\end{array}$ & $\begin{array}{c}\mathbf{W} \\
(\mathrm{mg} / \mathbf{g})\end{array}$ & $\begin{array}{c}\mathbf{C o} \\
(\mathbf{\%})\end{array}$ \\
\hline Union Co. & UC & U.S.A. & 3 & 6.12 & 54.8 & 245 & 2.200 & 0.65 & 4.65 & 2.13 & 0.45 \\
\hline Mount Dooling & MD & Austrália & 733 & 6.26 & 52.0 & 234 & 1.100 & 0.60 & 4.6 & 2.03 & 0.44 \\
\hline Bendegó & $\mathrm{Be}$ & Brasil & 5.360 & 6.39 & 54.0 & 234 & 0.210 & 0.76 & 6.0 & 1.78 & 0.47 \\
\hline Mournpowie & Um & Austrália & 1.143 & 6.42 & 41.8 & 85 & 1.980 & 0.61 & 4.5 & 1.64 & 0.44 \\
\hline Nocoleche & No & Austrália & 20 & 6.45 & 48.6 & 148 & 7.100 & 0.57 & 4.3 & 1.90 & 0.46 \\
\hline Arispe & Ar & México & 307 & 6.54 & 50.3 & 243 & 9.000 & 0.77 & 7.2 & 2.38 & 0.46 \\
\hline Santa Rosa & SR & Colômbia & 820 & 6.63 & 50.6 & 222 & 0.067 & 0.92 & 8.0 & 1.06 & 0.45 \\
\hline Chihuahua City & CC & México & 54 & 6.68 & 52.7 & 212 & 0.098 & 0.90 & 7.4 & 0.83 & 0.46 \\
\hline $\begin{array}{l}\text { Saint François } \\
\text { Co. }\end{array}$ & SF & U.S.A. & 7 & 6.77 & 49.2 & 247 & 0.098 & 0.96 & 8.7 & 1.45 & 0.45 \\
\hline Etosha & Et & Namíbia & 110 & 6.85 & 48.9 & 217 & 0.120 & 1.04 & 7.9 & 0.96 & 0.46 \\
\hline Winburg & Wi & África do & 50 & 6.98 & 51,8 & 180 & 0.89 & - & - & - & - \\
\hline
\end{tabular}

Tabela 4 - Análises químicas para o Meteorito Bendegó e amostras a ele associadas.

\begin{tabular}{|c|c|c|c|c|c|c|}
\hline \multirow{2}{*}{ Elemento } & \multirow{2}{*}{ Unidade } & Scott (1977) / INAA & Universidade Pisa & \multicolumn{3}{|c|}{ Becquerel / INAA } \\
\hline & & \multicolumn{3}{|c|}{ Meteorito Bendegó } & $\begin{array}{l}\text { Óxido Ferro do } \\
\text { Bendegó }\end{array}$ & $\begin{array}{l}\text { Rocha com veio } \\
\text { metálico }\end{array}$ \\
\hline $\mathrm{Ni}$ & $\mathrm{mg}$ & 63,9 & 68,5 & 61,4 & 32,9 & 0,692 \\
\hline Co & $\mathrm{mg}$ & 4,7 & 5,1 & 4,48 & 2,86 & 0,211 \\
\hline $\mathrm{Cr}$ & $\mathrm{mg}$ & & & 0,0580 & 0,0515 & 0,5590 \\
\hline S & $\mathrm{mg}$ & & & 0,5 & & \\
\hline As & microg & 6 & & 5,3 & 4,05 & 1,7 \\
\hline $\mathrm{Cu}$ & microg & & 144 & 157 & & \\
\hline $\mathrm{Ga}$ & microg & 54 & 54,7 & 56 & & \\
\hline $\mathrm{Ge}$ & microg & 234 & 235 & & & \\
\hline Mo & microg & & 7 & $<14$ & $<6$ & 0,27 \\
\hline $\mathrm{Ru}$ & microg & & 9,3 & 7,6 & & \\
\hline $\mathrm{Rh}$ & microg & & 2,17 & 1,85 & & \\
\hline $\mathrm{Pd}$ & microg & & 2,87 & 2,06 & & \\
\hline $\mathrm{Sn}$ & microg & & 0,53 & & & \\
\hline $\mathrm{Sb}$ & microg & & 0,08 & $<0.3$ & $<0.1$ & 0,061 \\
\hline W & microg & 1,78 & 2,31 & 7,2 & $<2$ & $<0.5$ \\
\hline $\mathrm{Re}$ & microg & & 0,01 & $<0.03$ & $<0.02$ & $<0.01$ \\
\hline $\mathrm{Ir}$ & microg & 0,21 & 0,22 & 0,171 & 0,135 & $<0,003$ \\
\hline $\mathrm{Pt}$ & microg & & 12,6 & 11 & & \\
\hline $\mathrm{Au}$ & microg & 0,76 & 0,8 & 0,693 & 0,435 & $<0,001$ \\
\hline
\end{tabular}

a presença de elevados percentuais de $\mathrm{Ni}(3,29 \%) \mathrm{e}$ Co $(0,28 \%)$, respectivamente $51,49 \%$ e $63,83 \%$ das concentrações no Bendegó. Uma amostra de rocha venulada (Fig. 8D) foi também analisada por INAA.
O veio metálico presente nesta amostra revelou uma alta concentração de $\mathrm{Cr}$ (559 ppm), superior comparativamente ao teor desse elemento no meteorito (59 ppm) enquanto que nas rochas do complexo Uauá, 
embasamento do Núcleo Serrinha no local do achado está abaixo do limite de detecção nos gnaisses e 40267 ppm nos anfibolitos (Rios 2002). Estes dados justificam a realização de pesquisas mais detalhadas para os veios metálicos que cortam esse tipo de rocha. As amostras foram encontradas na superfície e distando não mais do que $30 \mathrm{~m}$ do local provável do impacto do meteorito. São rochas félsicas, feldspáticas, sem estrutura gnáissica aparente, e que ocorrem de forma escassa, tendo sido encontrados apenas fragmentos soltos. A questão é se estes veios metálicos ricos em $\mathrm{Ni}$ e $\mathrm{Cr}$ seriam ou não evidências do choque.

Agradecimentos Os autores agradecem à Fundação de Amparo a Pesquisa do Estado da Bahia (FAPESB) que tem financiado trabalhos de popularização da meteorítica na Bahia e ao Museu Nacional (UFRJ) pela cessão de amostras do meteorito. D.C. Rios e $\mathrm{H}$. Conceição agradecem ao $\mathrm{CNPq}$ pela bolsa de produtividade em pesquisa.

\section{Referências}

Buchwald V.F. 1975. Handbook of iron meteorites: Their history, distribution, composition, and structure. Berkeley, University of California Press, Vols. 1, $2,3$.

Carvalho J.C. 1888. Meteorito de Bendegó. Relatório apresentando ao Ministério da Agricultura, Comércio e Obras Públicas e à Sociedade Brasileira de Geografia do Rio de Janeiro, sobre a remoção do Meteorito de Bendegó do Sertão da Bahia para o Museu Nacional. Rio de Janeiro, Imprensa Oficial, $64 \mathrm{p}$.

Carvalho J.C. 1928. Meteorito de Bendegó. Histórico do meteorito de Bendegó, tentativas feitas para sua remoção do sertão da província da Bahia para o Museu Nacional. Rio de Janeiro, 125 p.

Carvalho W.P. 1995. Os meteoritos e a história do Bendegó. Salvador, Bahia, T.A. Comunicação, 100 p.

Carvalho W.P. \& Zucolotto M.E. 2008. Dois novos meteoritos baianos aumentam a coleção brasileira para 57 exemplares. In: Encontro Nacional de Astronomia, 11, Maceió-AL, atas, CD-rom.

Chladni E.F.F. 1794. Über den Ursprung der von Pallas gefundenen und anderer ihr ähnlicher Eisenmassen, und über einige damit in Verbindung stehende Naturerscheinungen. Riga and Leipzig: J.F.Hartknoch, $63 \mathrm{p}$.

Cunha B.C. 1784. Oficio para Rodrigo José de Menezes. Lisboa, Portugal, Arquivo Histórico Ultramarino, Caixa 6, Doc. N. 11.664.

Cunha B.C. 1786. Oficio para Rodrigo José de Menezes. Arquivo Histórico Ultramarino, Lisboa, Portugal, Caixa 64, Doc. N. 12.455.

Curvelo W.S. 1958. Meteoritic Sulphides. Boletim do Museu Nacional, Rio de Janeiro, Nova Série Geologia, 27:2347.

Derby O.A., 1896. Estudo sobre o Meteorito Bendegó. Archivos do Museu Nacional, Rio de Janeiro, 9:89-184.

D'Orazio M. \& Folco L. 2003. Chemical analysis of iron meteorites by inductively coupled plasma-mass spectrometry. Geostandards Newsletter: The Journal of Geostandards and Geoanalysis, 27(3):215-225.

Goltrant O., Leroux H., Doukhan J.C., Cordier P. 1992. Formation mechanisms of planar deformation features in naturally shocked quartz. Physics of the Earth and Planetary Interiors, 74:219-240.

Howard E.C. 1802. Experiments and observations on certain stony and metalline substances which at different times are said to have fallen on the earth; also on various kinds of native iron. Philosophical Transactions of the Royal Society of London, Series A, 92(1):168-212.

Inda H.A.V., Souza A.G., Silva Filho A.A., Pires A.B., Portela A.C.P, Cavedon A.D., Sanchez B.A., Santos E.Z., Pereira F.S., Gonçalves J.C., Braga Neto L.F., Costa M.R.A., Damião R.N., Mossmann R., Oliveira V., 1976. Projeto rochas básicas e ultrabásicas de Euclides da Cunha. Relatório final. Rio de Janeiro, PROSPECT, SME-BA, 12 volumes.

Kracher A., Willis J., Wasson J.T. 1980. Chemical classification of iron meteorites: IX. A new group (IIF), revision of IAB and IIICD, and data on 57 additional irons. Geochim. Cosmochim. Acta., 44: 773-787.

Krot A.N., Keil K., Goodrich C.A., Scott R.D., Weissberg N.K. 2006. Classification of meteorites. In: A.M. Davis (ed.) Meteorites, comets and planets, Treatise on Geochemistry. Elsevier, 1:83-128.

Mascarenhas J.F. 1979. Evolução Geotectônica do PréCambriano do Estado da Bahia. In: Inda H.A.V. (ed.) Geologia e Recursos Minerais do Estado da Bahia. Textos Básicos. Salvador-BA, SME/com, 2: 57-165.

Mason B. 1962. Meteorites. New York, John Willey Inc., 274p.

McCall G.J.H., Bowden A.J., Howarth R.J. (eds.) 2005. The History of Meteoritics and Key Meteorite Collections: Fireballs, Falls and Finds. Geological Society, London, Special Publications, $256 \mathrm{p}$.

Menezes R.J. 1784. Oficio para Martinho de Mello e Castro. Lisboa, Portugal, Arquivo Histórico Ultramarino, Caixa 6, Doc. N. 11.663.

Menezes R.J. 1787. Oficio para Martinho de Mello e Castro. Lisboa, Portugal, Arquivo Histórico Ultramarino, Caixa 64, Doc. N. 12.454.

Mornay A.F. 1816. An Account of the Discovery of a Mass of Native Iron in Brazil (Bendego). Philosophical Transactions, 106:270-280.

Olsen E. 1964. Some Calculations Concerning the Effect of Nickel on the Stability of Cohenite in Meteorites. Geochimica et Cosmochimica Acta, 28:609-617.

Partsch P. 1843. Die Meteoriten oder von Himmel gefallenen Steine und Eisenmassen in K.K. Hof-MineralienKabinete zu Wien, 162 p.

Pedreira J. \& Costa F.D. 2008. D. João VI - Um Príncipe entre Dois Continentes. Companhia das Letras, São 
Paulo, 508 p.

Perry S.H. 1944. The Metallography of Meteoric Iron. U. S. National Museum Bulletin 184, 115 p.

Reichenback K.L. von. 1857. Über die Rinden der Meteorsteine. Annalen der Physik, 104:472-482.

Reichenback K.L. von. 1862. Über die näheren Bestandtheile des Meteoreisens. Annalen der Physic und Chemie, 115:148-149 \& 151.

Rios D.C., Davis D.W., Conceição H., Davis W.J., Rosa M.L.S., Dickin A.P. 2009. Geologic evolution of the Serrinha nucleus granite-greenstone terrane (NE Bahia, Brazil) constrained by $\mathrm{U}-\mathrm{Pb}$ single zircon geochronology. doi:10.1016/j. precamres.2008.10.001. Precambrian Research, 170:175-201.

Rios D.C. 2002. Granitogênese no Núcleo Serrinha: Litogeoquímica e Geocronologia. Tese de Doutorado, Curso de Pós-Graduação em Geologia, Universidade Federal da Bahia, 238 p.

Rose G. 1864. Beschreibung und Eintheilung der Meteoriten auf Grund der Sammlung im mineralogischen Museum zu Berlin, 138 p.

Scott E.R.D. 1977. Composition, Mineralogy and Origin of Group IC Iron Meteorites. Earth and Planetary Science Letters, 37:273-284.

Scott E.R.D. \& Wasson J.T. 1976. Chemical classsification of iron meteorites - VIII. Groups IC, IIE, IIIF and 97 other irons. Geochimica et Cosmochimica Acta, 40:103-115.

Spix J. B. von \& Martius C.E.P. von. 1823. Reise in brasilien auf befehl Sr. Majestat Maximilian Joseph I, Konigs Von Baiern, in den jahren 1817 bis 1820 gemacht und beschrieben. Munchen. M. Lindauer. Tradução brasileira Lahmeyer L.F. 1938. Viagem pelo Brasil 1817-1820. $2^{\mathrm{a}}$ ed., São Paulo, Edições Melhoramentos, 3v. 412 p.

Story-Maskelyne N.H., 1863a. Catalogue of the collection of meteorites, in the British Museum, $4 \mathrm{p}$.

Story-Maskelyne N.H. 1863b. On aerolitics and the fall of stones at Butsura, India. May 1861. The American Journal of Science and Arts. Second Series, XXXVI, November 1863, 64-76.

Vidal N. 1936. Meteoritos Brasileiros. Boletim do Museu Nacional, 12:91-109.

Ward H. A. 1892. Illustrated Descriptive Catalogue of Meteorites. New York, Ward's Natural Science Establishment Rochester, 75, 8 p.

Wasson J.T., Choi B-G, Jerde E.A., Ulff-Moller F. 1998. Chemical classification of iron meteorites - XII. New members of the magmatic groups. Geochimica et Cosmochimica Acta, 62:715-724.

Wasson J.T. 1974. Meteorites - Classification and Properties. Springer, $316 \mathrm{p}$.

Wasson J.T., Huber H., Malvin D. 2007. Formation of IIAB iron meteorites. Geochimica et Cosmochimica Acta, 71:760-781.

Wasson J.T., Kallemeyn G.W. 2002. The IAB iron-meteorite complex: A group, five subgroups, numerous grouplets, closely related, mainly formed by crystal segregation in rapidly cooling melts. Geochimica et Cosmochimica Acta, 66(13): 2445-2473.

Wöhler F. 1860. Neure Unterscuchungen über die Bestandtheile dês Meteorsteines vom Capland. Sitzber. Akad. Wiss. Wien. Math-naturw. Kl. 41:565-567.

Wollaston W.H. 1816. Observations and experiments on the mass of native iron found in Brazil. Philosophical Transactions, 106:281-285.

Wülfing E.A. 1897. Die Meteoriten in Sammlungen und ihre Literatur, nebst einem Versuch, den Tauschwerth der Meteoriten zu bestimmen. Tübingen, Laupp'sche Verlagsbuchhandlung, $460 \mathrm{p}$.

Manuscrito ID 16640

Submetido em 22 de janeiro de 2010 Aceito em 30 de junho de 2011 